\title{
"O PORTO NÃO SE VENDE": RESISTÊNCIAS À GENTRIFICAÇÃO ATRAVÉS DA PRODUÇÃO ARTÍSTICA NO PERÍODO PÓS-AUSTERITÁRIO
}

\author{
Inês Barbosa \& João Teixeira Lopes ${ }^{1}$ \\ Instituto de Sociologia da Universidade do Porto, Portugal
}

\begin{abstract}
Explorando a hipótese de que os processos de turistificação em Portugal têm especificidades próprias relacionadas com as consequências da crise e da austeridade, este artigo centra-se nas resistências que têm vindo a ser desenvolvidas pelo direito à habitação no Porto. Foca-se em particular na designada "arte socialmente comprometida", apresentando quinze projetos realizados entre 2018 e inicio de 2020. A partir dessas produçóes artísticas são discutidos aspetos associados ao processo de criação; ao contexto e estratégias de comunicação; aos objetivos e discursos subjacentes, salientando também algumas tensóes e paradoxos existentes. Terminamos com breves reflexóes sobre o papel da arte e dos/as artistas na construção e disseminação da critica à gentrificação.
\end{abstract}

Palavras-chave: artistas, resistências, direito à habitação, gentrificação

\section{INTRODUÇ̃̃O}

Um mês depois da manifestação da "Geração à Rasca" - que juntou na Avenida dos Aliados, no Porto, cerca de 80000 pessoas - um coletivo de jovens, maioritariamente apartidários, ocupou e requalificou uma escola desativada há cinco anos, transformando-a no Espaço Colectivo Autogestionado (Es.Col.A) [8], um projeto educativo e cultural de portas abertas à população. A experiência durou pouco, depois de alguns episódios de resistência, a escola foi despejada. A história da ocupação da Fontinha haveria de dar origem a um documentário, realizado pelo coletivo Viva Filmes e, mais tarde, a inspirar o rap "Desobedece" de Expeão, Rey e Chullage. Este é um exemplo de como arte, cultura e mobilizações pelo direito à cidade se vão contaminando, gerando forças coletivas.

1 Contacto dos autores: inesbarbosa83@gmail.com

2 Protesto que impulsionou o ciclo de mobilização coletiva, em Portugal, entre 2011-2013. 
As temáticas da gentrificação e turistificação têm estado na ordem do dia, no âmbito nacional (e.g. Antunes et al, 2019a) e internacional (e.g. Schuerman, 2019). Em causa estão os seus impactos na transformação das cidades e da vida dos seus habitantes, nomeadamente no aprofundamento das desigualdades sociais, culturais e urbanas (Smith, 1996). Em Portugal, o fenómeno é relativamente recente, podendo ser associado ao contexto de crise e austeridade (2011-2014) altura em que, para além de alterações legislativas no campo da educação ou saúde, impostas pelo Memorando da Troika, foram criados mecanismos no setor da habitação baseados num modelo não intervencionista e neoliberal: Autorização de Residência para Atividade de Investimento (vulgo, Vistos Gold), Regime Legal do Arrendamento Local, Regime Excepcional de Reabilitação Urbana ou Regime Jurídico de Reabilitação Urbana (Antunes, 2019b).

À época, o Porto debatia-se com o decrescimento da população no centro histórico (Censos, 2011), com um número elevado de edifícios devolutos e níveis de pobreza e exclusão social dilatados com a crise (Alves, 2017). Coincidindo com esse período, inicia-se uma espiral ascendente de prémios e louvores, ${ }^{3}$ atingindo-se níveis record de turistas, fenómeno que não tem dado sinais de abrandamento (Gúsman, 2019). A cidade torna-se uma marca. Os números são evidentes: de Agosto de $2009^{4}$ a Agosto de 2019, o número de passageiros a passar pelo aeroporto subiu 169\% (dados do INE). Já as propriedades listadas no AIRBNB subiram de 10 para 100 mil, entre 2010 e 2018 (Fernandes et al, 2018). No período pós-austeritário, o turismo surge como "panaceia para a crise social e urbana" (Mendes, 2017), uma oportunidade para expandir, radicalizar e aprofundar os processos de gentrificação (Janoschka, 2018). Tal como noutros países, como Espanha e Grécia, a turistificação terá traços específicos relacionados com baixos salários, precariedade generalizada e uma estratégia dos governos fazendo do turismo um motor privilegiado de recuperação da economia.

Esse boom turístico tem tido, evidentemente, consequências. Se, por um lado, tem instigado a reabilitação e a revitalização do centro histórico e do comércio, por outro, assiste-se ao aumento abrupto do valor da habitação; a despejos em massa e pressão sobre moradores; e ao encerramento de estabelecimentos e espaços associativos. Outros fenómenos como a sobrevalorização da baixa, política de fachadismo ou a aposta nas "indústrias criativas" apontam para uma progressiva mercantilização da cidade (Queirós, 2017). Dados recentes da OCDE (2019), revelam uma classe média sob pressão, em particular pelo peso que a habitação tem nos orçamentos familiares, sendo Portugal um dos países onde as rendas mais subiram $(33,2 \%)^{5}$. No Porto, dificilmente se encontra um T1 por menos de 550 euros, num país onde o ordenado mínimo é de 735 euros e o médio de 943 euros. Os números apontam ainda para cerca de 100 famílias despejadas todos os anos $^{6}$. Para além das classes populares e da população envelhecida, a "Geração Milénio" é um dos segmentos mais afetados pelas dificuldades de inserção no mercado da habitação ${ }^{7}$, em grande parte devido aos frágeis vínculos laborais (Ferreira et al, 2017).

3 Em 2012, 2014 e 2017, Melhor Destino Europeu” (European Consumers Choice); em 2013, Melhor Destino de férias na Europa (Lonely Planet); 2015 Top 10 polos turísticos (the Guardian); 2018, Melhor destino europeu e $2^{\circ}$ melhor mundial (Culture Trip).

4 Ano em que a companhia aérea low cost, Ryanair, se instala no Porto.

5 Https://www.oecd.org/social/under-pressure-the-squeezed-middle-class-689afed1-en.htm

6 Https://expresso.pt/revista-de-imprensa/2019-03-15-Camaras-de-Lisboa-e-Porto-despejam-100-familias-por-ano

$745,6 \%$ dos jovens portugueses entre os 25 e os 34 anos vive em casa dos pais quando a média europeia é 28,5 $\%$ (Eurostat). 
Por tudo isto, no Porto, como noutras cidades europeias e mundiais, tem-se assistido à proliferação de formas de contestação contra a turistificação (Colomb \& Novy, 2017) que parecem beber dos ensinamentos e práticas das mobilizações "pró-democracia e anti-austeridade" protagonizadas, maioritariamente, por jovens precários (Della Porta, 2014). Não só protestos, debates e grupos ativistas, mas também filmes, performances, música ou arte urbana. Neste artigo quisemos evidenciar a efervescência da produção artística relacionada com o direito à habitação, enquadrada numa "arte socialmente comprometida" (Castellano \& Raposo, 2019). Começamos por construir uma cronologia das mobilizações coletivas dos últimos anos, dando conta da constituição de canais e plataformas ativistas; do encerramento de espaços "subversivos" e culturais da cidade; dos momentos de protesto e debate público; assim como dos acontecimentos mais mediatizados. Em seguida, apresentamos um conjunto de quinze iniciativas artísticas, realizadas no Porto, entre 2018 e início de 2020. A partir delas discutimos as suas especificidades (processo de criação; contexto e estratégias de comunicação; objetivos e discursos), salientando também algumas tensões e paradoxos inerentes. Terminamos o artigo com breves reflexões sobre o papel da arte e dos/as artistas na construção e disseminação da crítica contra a gentrificação e pelo direito à cidade.

\section{MOBILIZAÇÕES PELO DIREITO À HABITAÇÃO NO PORTO}

Em 2015 - já depois da saída da Troika e do anunciado “fim da crise” - Miguel Januário, o street artist conhecido por Mais Menos, espalhava pela cidade um dos seus trabalhos mais emblemáticos: "Antiga, mui gourmet, sem plano social e turística cidade do Porto". Denunciando a inversão de prioridades das políticas municipais, o stencil faz um trocadilho com o epíteto "Antiga, mui nobre, sempre leal e invicta" que consta do brasão da cidade em referência às resistências históricas. Essa mesma inscrição é integrada num imenso painel de azulejos (cerca de 3300) construído em colaboração com a comunidade local e coordenado pelo artista, projeto esse financiado pela Câmara Municipal do Porto (CMP), um paradoxo que tem marcado parte das intervenções artísticas sobre a gentrificação e que será discutido mais adiante.

Nesse mesmo ano, começam a suceder-se alguns episódios de deslocamento e encerramento. Destaca-se o fecho da Casa Viva [5], um projeto libertário com forte dinamismo cultural e artístico, implantado há uma década num edifício cedido na Praça do Marquês; o fim da Alma em Formol [1], um espaço de concertos punk na Rua do Almada, uma das zonas mais centrais do Porto e a transferência da Feira da Vandoma das Fontainhas [10] para a freguesia de Campanhã, provocando a indignação dos vendedores/as e da população em geral. A contestação foi tomando corpo com a formação de plataformas ativistas, algumas assumindo-se como canais virtuais de denúncia, como é o caso das páginas Nojentrificação (criada em Junho de 2016 e ainda em atividade); Cartas ao Rui (que durou apenas seis meses) ou o grupo "Porto," (também inativo); outras combinando o ativismo nas redes sociais com a criação de núcleos participativos: Habita Porto, Assembleia de Moradoras/es do Porto, O Porto Não se Vende e o Direito à Cidade, dos quais, apenas os últimos dois vão mantendo uma atividade esporádica.

Em 2017, encerram outros espaços importantes para o circuito artista e ativista: o Contrabando [7], associação que organizava debates e eventos culturais; ou Cave 45[6], bar de concertos punks e metal. Dá-se também uma tentativa de ocupação de uma escola, Travessa 
Okupada $^{8}[24]$, que dura apenas uns dias, sendo rapidamente despejada pelas forças policiais. Nesse Verão, a ampla disseminação do stencil e autocolante "Porto Morto" - uma subversão da marca "Porto, Ponto" da CMP - causa a indignação do presidente Rui Moreira, ao ponto deste apresentar queixa contra autor desconhecido9. Em Setembro desse ano, acontece a primeira concentração do Porto Não se Vende com uma participação tímida de uma centena de pessoas. Em 2018 dá-se continuidade à contestação nas ruas e em debates públicos. Organizam-se fóruns de discussão em espaços culturais e de resistência, como a Rosa Imunda [21] e a Filó [9] ${ }^{10}$, assim como churrascos populares e cinco momentos de protesto num espaço de apenas seis meses: Concentração pelo Direito à Cidade [3], Concentração Porto Não se Vende, Marcha pelo Pelo Direito à Habitação [16], Manifestação Nacional pelo Direito à Habitação e a Acampada dos Estudantes pelo Alojamento [17]. Porém, o ano é também de derrotas, com o despejo do Quiosque do Piorio [19], sede física da Porto Worst Tours ${ }^{11}$ depois de meses de resistência (cartas abertas, abaixos-assinados, etc); o anúncio do encerramento da livraria anarquista Gato Vadio [12] e mais uma tentativa falhada, desta vez de abertura de um novo espaço para a Casa Viva.

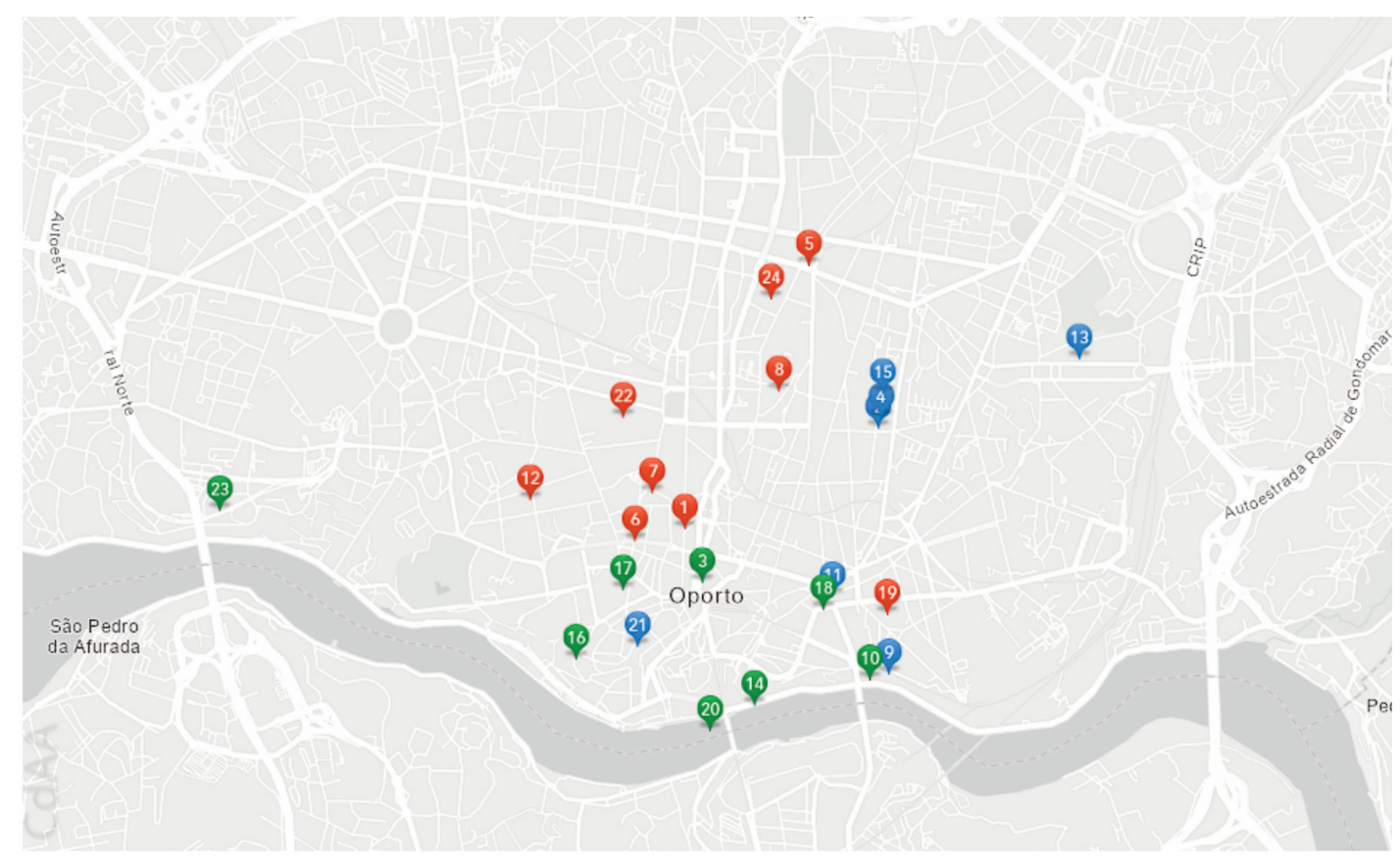

Foto 1 - Mapa dos principais territórios mencionados no artigo, da autoria de Manuel Garcia-Ruiz. Vermelho (espaços encerrados), Azul (espaços abertos), Verde (outros locais da cidade).

O ano seguinte é marcado por polémicas: queda de duas gruas em zonas centrais do Porto, fruto, aparentemente, da urgência e desleixo na construção; embargo da construção junto à Ponte da Arrábida pelo Ministério Público; contestação popular nas Fontainhas [10] e conse-

8 Estão ainda a ser organizadas festas de angariação de fundos para pagamento de despesas legais com esse processo.

9 Https://observador.pt/2017/08/07/morto-em-vez-de-porto-camara-apresenta-queixa/

10 P.ex: I e II Encontro pelo Direito à Cidade, Café Ceuta; I e II Jornadas Cidade em Revolta (Rosa Imunda e Filó)

11 O projeto Worst Tours, existente desde 2012, promove passeios pelo lado B da cidade (espaços abandonados, desconhecidos ou de resistência). 
quente interrupção das obras; incêndio criminoso no edifício do Bolhão fruto da especulação imobiliária; alteração "gourmet" do Miradouro da Vitória [14] e reação imediata da população; ou demolição das últimas Torres do Aleixo para construção de um condomínio de luxo. Em 2019 fecha o espaço comunitário Rés-da-Rua [22] mas, por seu turno, abrem dois projetos de cariz libertário e ativista: Gralha - Centro Social Auto-Gerido [4] onde se reúne o recém-criado Grupo de Apoio à Habitação (GAH); e MalDatesta [13], uma livraria e espaço associativo. Ainda assim, nenhuma concentração pública é marcada nesse ano.

O início de 2020 principia com duas situações controversas que reativaram a mobilização coletiva: despejo de uma moradora da Ribeira [20] e dos seus dois filhos menores que levou à imediata contestação popular; ${ }^{12}$ e censura da folha de sala, escrita por Regina Guimarães, para a peça "Turismo" que originou a denúncia de outras situações similares envolvendo artistas do Porto; um abaixo-assinado pela liberdade na cultura e a demissão da artista do conselho cultural da CMP.

\section{PRODUÇões ARTísticAs CONTRA A GENTRIFICAÇÃo NO PORTO (2018-2020)}

Acompanhando a contestação contra a gentrificação que tem ocorrido no Porto, vários/ as artistas têm vindo, nos últimos anos, a utilizar a arte como ferramenta política de denúncia. No âmbito de uma pesquisa autónoma, procedeu-se ao mapeamento das produções artísticas realizadas ou apresentadas entre 2018 e início de 2020. Selecionamos quinze que são um bom retrato da pluralidade de estilos, estratégias e objetivos. Começamos por descrevê-las, de forma sucinta, apresentando-as cronologicamente.

Os trabalhos de Pedro Figueiredo [A] - um dos arquitetos responsáveis pela Worst Tours - ilustram alguns dos episódios da vida portuense, fazendo uso da ironia e do humor para tecer as suas críticas. Desde a proliferação de hotéis e airbnbs pela cidade; ao embargo das obras na Arrábida; passando pela deslocação da Feira da Vandoma; a demolição das torres do Aleixo; as filas de turistas na livraria Lello; ou a queda acidental das gruas (foto 1). "Porra" [B] é um azulejo criado por 3 Pontinhos [2], alter-ego de Luís Carvalho, a partir da subversão da imagem de marca do município, "Porto Ponto". Escrito com reticências e aliado a uma figura fálica, o azulejo sugere um misto de desalento e insurreição. O artista é também responsável pela série de trabalhos em escultura e stencil "O meu coração ficará no Porto" que critica os despejos dos moradores a partir de um ponto de vista emocional. "Gentrificasamba ${ }^{13}$ " [C] é uma canção dos Samba sem Fronteiras, coletivo de músicos brasileiros. A letra, escrita por Luca Argel, enumera os sucessivos encerramentos (florista, taberna, confeitaria, alfarrabista), usando do sarcasmo para apontar as desigualdades e privilégios associados à turistificação. $\mathrm{O}$ videoclip, produzido pelos próprios músicos, mostra o interior do quiosque do Piorio [19] coberto de cartazes e slogans pelo direito à habitação. A performance 100 Lar [D] foi também apresentada por ocasião da festa de encerramento do Quiosque que reuniu um conjunto de artistas em instalações, concertos, performances, culminando num cortejo fúnebre, um incêndio simbólico e o revestimento da totalidade do quiosque com tinta negra. Protagonizada por duas jovens estrangeiras (Flora Paim e Inés Ballesteros), estudantes de Belas-Artes, a performance simulava uma "equi-

12 Https:/www.publico.pt/2020/02/07/culturaipsilon/noticia/polemica-regina-guimaraes-traz-luz-historial-censura-teatro-municipal-porto-1903331

13 Videoclip de "Gentrificasamba": https://www.youtube.com/watch?v=OYt_hr-qfCI 
pa de agentes especuladores especializados em encontrar áreas livres e frestas ainda disponíveis na cidade neoliberal". ${ }^{4}$

\begin{tabular}{|c|c|c|c|c|c|}
\hline & Título/Descrição & Tipologia & Autores/as & Data & Contextualização \\
\hline A & $\begin{array}{l}\text { Ilustrações (episódios } \\
\text { da cidade) }\end{array}$ & $\begin{array}{l}\text { Artes } \\
\text { plásticas }\end{array}$ & $\begin{array}{l}\text { Pedro } \\
\text { Figueiredo }\end{array}$ & $2018 / 19$ & $\begin{array}{l}\text { Divulgação regular na página } \\
\text { pessoal do autor }\end{array}$ \\
\hline B & $\begin{array}{l}\text { Porra! \& O meu } \\
\text { coração ficará no Porto }\end{array}$ & $\begin{array}{l}\text { Arte urbana } \\
\text { (cerâmica) }\end{array}$ & Zé Pontinhos & $2018 / 19$ & $\begin{array}{l}\text { Peças colocadas em vários lugares } \\
\text { da cidade e divulgadas no facebook }\end{array}$ \\
\hline $\mathrm{C}$ & Gentrificasamba & Música & $\begin{array}{l}\text { Samba sem } \\
\text { Fronteiras }\end{array}$ & $27 / 05 / 18$ & Filmado no Quiosque do Piorio \\
\hline $\mathrm{D}$ & $100 \mathrm{Lar}$ & Performance & $\begin{array}{l}\text { Flora Paim e } \\
\text { Inés Ballesteros }\end{array}$ & $01 / 06 / 18$ & $\begin{array}{l}\text { Encerramento do Quiosque do } \\
\text { Piorio }\end{array}$ \\
\hline $\mathrm{E}$ & $\begin{array}{l}\text { Faixa "Rebenta a } \\
\text { Bolha" }\end{array}$ & $\begin{array}{l}\text { Artes } \\
\text { plásticas }\end{array}$ & Desconhecido & $22 / 09 / 18$ & $\begin{array}{l}\text { Colocado numa ponte durante o } \\
\text { percurso da manifestação }\end{array}$ \\
\hline $\mathrm{F}$ & $\begin{array}{l}\text { Cães que ladram aos } \\
\text { pássaros }\end{array}$ & Cinema & Leonor Teles & $16 / 12 / 18$ & $\begin{array}{l}\text { Financiado pelo programa "Cultura } \\
\text { em Expansão" (CMP) }\end{array}$ \\
\hline G & Cidade Líquida & Arte urbana & Mais Menos & $24 / 02 / 19$ & Divulgado nas redes sociais \\
\hline $\mathrm{H}$ & $\begin{array}{l}\text { CriptoPorto-Necropsia } \\
\text { de uma cidade }\end{array}$ & $\begin{array}{l}\text { Artes } \\
\text { Plásticas }\end{array}$ & Dr. Urânio & $06 / 04 / 19$ & $\begin{array}{l}\text { Exposta no Atelier Logicofobista } \\
\text { (gerido pelo autor) }\end{array}$ \\
\hline I & PortoArder! & Música & Grito! & $25 / 05 / 19$ & Apresentação no Barracuda \\
\hline $\mathrm{J}$ & $\begin{array}{l}\text { A Contra Cidade: } \\
\text { Buraco da Torre }\end{array}$ & $\begin{array}{l}\text { Literatura } \\
\text { Artes } \\
\text { plásticas }\end{array}$ & $\begin{array}{l}\text { Cerca de } 100 \\
\text { participações }\end{array}$ & $13 / 06 / 19$ & $\begin{array}{l}\text { Lançamento na Oficina Arara, } \\
\text { durante a Feira da Alegria }\end{array}$ \\
\hline K & Demolição Social & Fotografia & Luís Coelho & $20 / 07 / 19$ & $\begin{array}{l}\text { Exposição na Galeria Geraldes da } \\
\text { Silva }\end{array}$ \\
\hline $\mathrm{L}$ & $\begin{array}{l}\text { Best Tourism } \\
\text { Destination }\end{array}$ & Arte urbana & Desconhecido & $09 / 2019$ & $\begin{array}{l}\text { Pintado na Praça dos Poveiros } \\
\text { (apagado em poucas semanas) }\end{array}$ \\
\hline M & Circunvalação & Música & Capicua & $23 / 01 / 20$ & Lançamento na internet \\
\hline $\mathrm{N}$ & Turismo & Teatro & $\begin{array}{l}\text { Tiago } \\
\text { Correia/Turma }\end{array}$ & $31 / 01 / 20$ & $\begin{array}{l}\text { Apresentação no Teatro Municipal } \\
\text { Campo Alegre }\end{array}$ \\
\hline $\mathrm{O}$ & Olhos fechados & Arte urbana & $\begin{array}{l}\text { Itay Peleg e } \\
\text { Marta Vidal }\end{array}$ & $01 / 02 / 20$ & $\begin{array}{l}\text { Passeio das Virtudes, projeto } \\
\text { divulgado no "Porto Não se vende" }\end{array}$ \\
\hline
\end{tabular}

Tabela 1. Produções artísticas contra a gentrificação no Porto (2018-2020).

A faixa "Rebenta a Bolha" [E] colocada numa ponte junto à Ribeira [20], durante o trajeto da marcha "O Porto Não se Vende" é de autoria desconhecida. A faixa expunha duas figuras disformes ameaçando moradores/as e suas casas, metaforizando a bolha imobiliária, num confronto desequilibrado entre eles (os poderosos, grandes, especuladores) e os outros (o povo pequeno e as suas casas). A expressão "rebenta a bolha"15parece instigar à ação popular, como um "jogo" injusto que tem de ser interrompido. O filme "Cães que ladram aos pássaros" $[\mathrm{F}]$, de Leonor Teles, foi realizado no âmbito de uma residência artística do programa "Cultura em

14 Https://www.publico.pt/2018/05/31/local/noticia/o-adeus-ao-quiosque-do-piorio-ou-o-sonho-impossivel-de-uma-outra-cidade-1832693

15 Na gíria significa que o jogo acabou porque houve batota ou não há condições para continuar. 
Expansão" da CMP. Entre o documentário e a ficção, a história parte da experiência pessoal de uma família em situação de despejo para discutir as rápidas transformações urbanas no Porto fruto dos processos de gentrificação. O stencil "Cidade Líquida" [G] é assinado por Mais Menos, Miguel Januário. A escolha do termo ${ }^{16}$ parece advir de uma crítica às políticas públicas urbanas no Porto, em que tudo é instável e nada permanece: a habitação que ocupamos, as ruas que percorremos, a cidade como a conhecemos. Na mesma altura, outros grafitti anónimos foram inscritos nas paredes: "Cidade líquida, cidade liquidada".

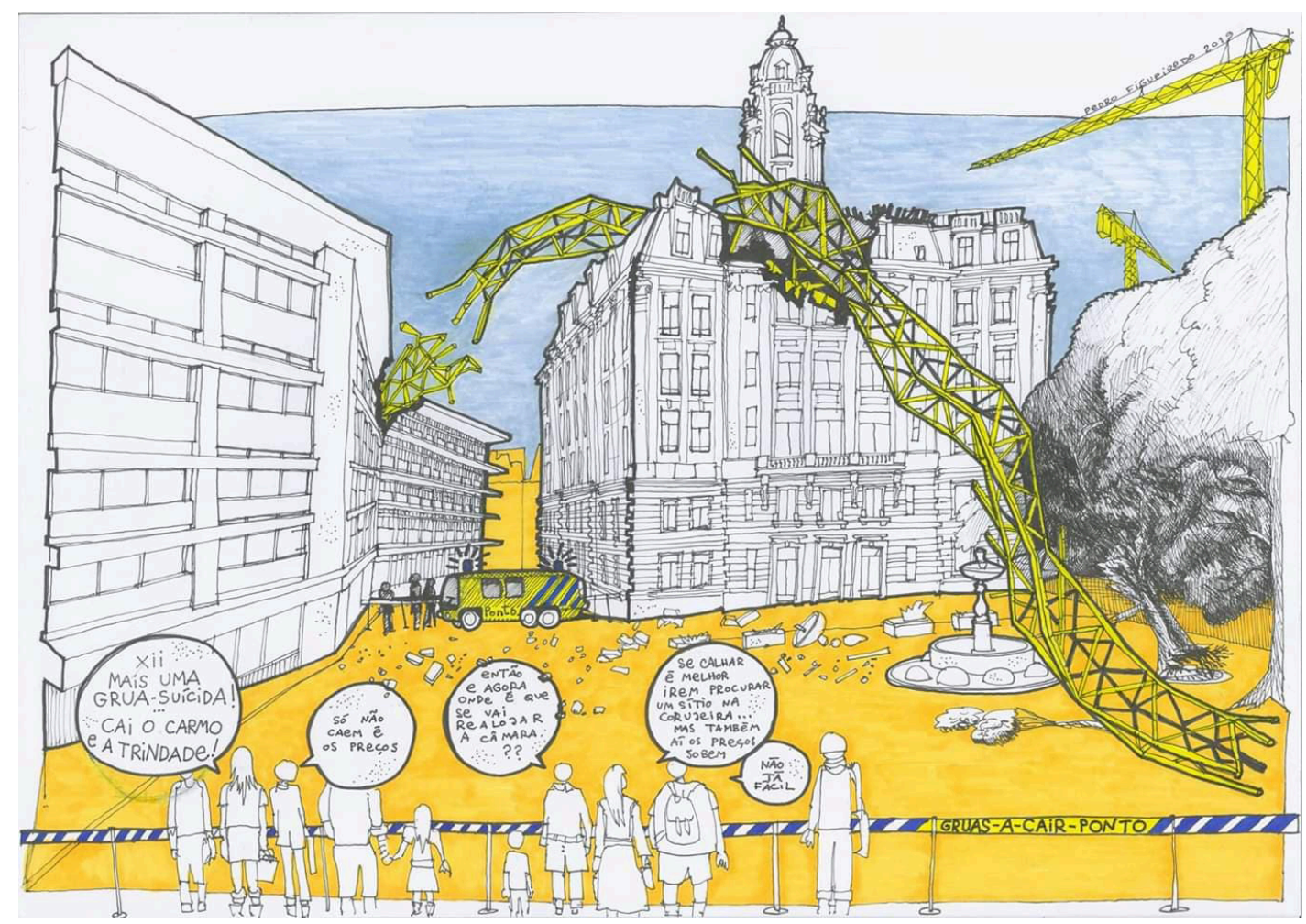

Foto 2. Ilustração de Pedro Figueiredo sobre a queda das gruas, 2019.

Na exposição “CriptoPorto: necropsia de uma cidade” [H], Dr. Urânio, o artista plástico que dirige o Atelier Logicofobista [2], exibiu a sua vasta coleção de mapas, fotografias e recortes de jornal, em que era possível identificar alguns dos acontecimentos e personagens marcantes do Porto: espaços encerrados, controvérsias políticas, lutas e oposições populares, entrelaçadas numa rede de fios de lã. Na música Porto a Arder! ${ }^{17}[\mathrm{I}]$, da emblemática banda punk Grito!, a letra e o vídeo contam a história recente da cidade: excertos de reportagens sobre o incêndio no Bolhão, despejos e bullying imobiliário, demolição das Torres do Aleixo; acompanhadas de imagens sobre o direito à habitação e outras que refletem um imaginário do Porto "autêntico": popular, insurgente, arruaceiro. A publicação "A Contra Cidade" [J], editada pela Oficina Arara [15], coletivo e estúdio de serigrafia, também se debruça sobre a questão da habitação. Contando com a participação de quase uma centena de artistas, a edição especial do "Buraco da Torre” expõe os dilemas e debates em torno da gentrificação e especulação imobiliária, através de crónicas, poesia, fotografias e ilustrações.

16 É também uma resposta à expressão utilizada por Paulo Cunha e Silva, vereador da cultura já falecido. https:// www.publico.pt/2020/02/21/culturaipsilon/opiniao/proposito-cidade-liquida-usos-abusos-conceitos-1904929

17 Videoclip de "Porto a Arder!" https://www.youtube.com/watch?v=RVcLHq7Ku34 
A exposição "Demolição Social” [K], de Luís Coelho, foi exposta na Galeria Geraldes da Silva [11]. Trata-se de um conjunto de fotografias a preto e branco de estaleiros de obras, interiores de casas destruídas e da paisagem de gruas que povoa a cidade. No texto do evento, no facebook, lia-se: "Porto, cidade em processo de demolição social, onde a gentrificação é lei e o fachadismo é moda". "Best European Destination" [L] é um mural pintado na Praça dos Poveiros [18] de autoria desconhecida. A imagem (foto 3) representa o presidente Rui Moreira, nu e em pose sedutora, como que o acusando de ter vendido a cidade ao turismo. O mural foi pintado de branco poucas semanas depois. "Circunvalação"18 [M] é uma das canções do álbum mais recente da rapper Capicua. A letra celebra o Porto "castiço" e "típico", denunciando a substituição da cidade "genuína" por uma cidade gourmet e standardizada, semelhante a qualquer outra. É, ao mesmo tempo, uma crítica à segregação dos portuenses para a periferia e um apelo à mobilização, em nome do "direito à cidade". ${ }^{19}$

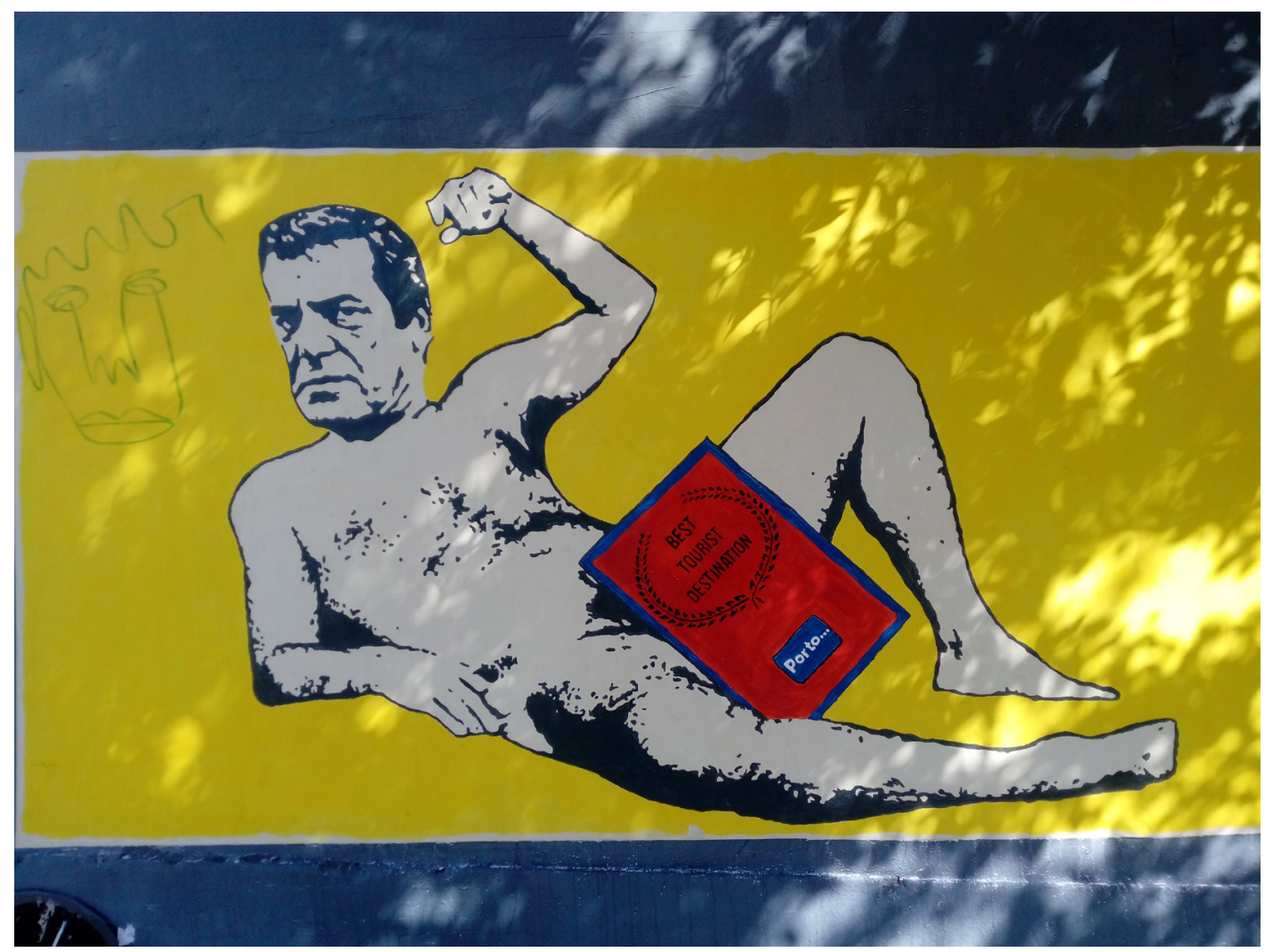

Foto 3 - "Best European Destination”, Praça dos Poveiros (Foto de Inês Barbosa).

“Turismo" [N] é uma peça de teatro, escrita por Tiago Correia, interpretada pela Turma e apresentada no Teatro Municipal do Campo Alegre [23]. A peça focava nas contradições da turistificação, a jovem inquilina que subarrenda o seu apartamento para fazer face às despesas; o senhorio, também em situação precária que se vê na inevitabilidade de vender a casa; o turista que, sendo crítico, também contribui para todo esse novelo. Por fim, "Olhos fechados" [O] um projeto em curso do fotógrafo Itay Peleg e da jornalista independente Marta Vidal ${ }^{20}$, é um

18 Música "Circunvalação”: https://www.youtube.com/watch?v=LDKuKfgRut0

19 Entrevista a Capicua: https://blitz.pt/principal/update/2020-02-01-As-visoes-Madreperola-de-Capicua.-Uma-conversa-intensa-sobre-libertacao-gentrificacao-feminismo-ecologia-e-redes-sociais

20 A reportagem de Marta Vidal que inspirou o projeto "Olhos fechados": https://www.opendemocracy.net/ en/can-europe-make-it/gentrification-in-porto-will-city-turn-into-hotel/ 
conjunto de colagens espalhadas pela cidade, onde se vê o rosto e testemunho de um morador de um bairro antigo da cidade, falecido, alegadamente devido à pressão provocada pela ordem de despejo da sua casa.

\section{Processos, estratégias e contextos na criação artística}

Os quinze exemplos de produções artísticas que mapeamos, entre 2018 e 2020, assumem características muito distintas, tanto no que se refere ao processo de criação, como à forma e linguagem empregada, estratégias de comunicação utilizadas ou contexto em que foram exibidas. Muitas dessas diferenças resultam em tensões ou paradoxos que vale a pena salientar.

A maioria das criações reveste-se de autoria, a excepção é a faixa "Rebenta a bolha" e o mural "Best Tourism Destination". Esse mural é apenas um dos exemplos de uma série de manifestações visuais que têm surgido nas paredes da cidade, algumas com uma preocupação mais estética, outras menos, mas todas elas sem assinatura (Barbosa \& Lopes, 2019). Há também situações ambivalentes, como é o caso dos azulejos de 3 Pontinhos ou do projeto "Olhos Fechados". No caso do primeiro, este só assumiu a autoria recentemente, numa entrevista ao Público, porém o seu nome não aparece junto das obras; a autoria do segundo foi divulgada através da página virtual do coletivo ativista "O Porto Não se Vende", ainda que, quem passar pelos cartazes ou murais do projeto, não terá como saber quem os fez e em que contexto. $\mathrm{O}$ anonimato poderá servir como forma de garantir a proteção dos artistas que podem não querer ser expostos ou associados às suas obras. A não-autoria pode servir também para dar um sentido coletivo à obra artística e a uma luta que é de todos/as. É o que poderá ter acontecido no caso do "Rebenta a Bolha" cuja execução teve o apoio de membros da Rosa Imunda [21], um espaço feminista e libertário situado numa das zonas mais afetadas pela gentrificação. A ausência de autoria pode, contudo, ocasionar equívocos. Numa ocasião, foram pintadas lágrimas azuis em várias estátuas da cidade, não tendo a "obra" sido reclamada por ninguém. Ainda que possamos interpretá-la à luz de uma crítica das transformações urbanísticas, nada nos garante que o seu sentido não seja diametralmente distante. Nem tão pouco é evidente se se tratou de uma produção artística ou de um ato de vandalismo como o classifica a notícia. ${ }^{21}$

Os trabalhos que trouxemos a debate também se distinguem pelo facto de serem fruto de um processo coletivo ou individual. A exposição de fotografias de Luís Coelho ou a letra da Capicua contrastam com trabalhos elaborados por um conjunto mais ou menos alargado de pessoas: a música "Porto a Arder" cuja autoria é assumida pelo conjunto da banda; ou a peça "Turismo" que, ainda que tenha sido escrita pelo encenador, foi interpretada pelos atores e atrizes e, como tal, apropriada por eles/as. Já "A Contra Cidade”, apesar de ter sido editada por um coletivo, mantém traços individuais, na medida em que cada participação é assinada por um/a artista. Ainda que muitas das produções artísticas tenham sido realizadas por uma só pessoa, é notória a existência de redes de troca e partilha entre os artistas e os lugares que estes ocupam. Se não, vejamos: o único exemplar do azulejo "Porra" foi colocado no Quiosque do Piorio um projeto do ilustrador Figueiredo. Este foi também o lugar onde foi filmado o videoclip do "Gentrificasamba" e onde foi apresentada a performance 100 Lar. A exposição "Demolição Social" foi exibida na galeria onde trabalha 3 Pontinhos; e o atelier Logicofobista [2] fica na

21 Https://www.jn.pt/local/noticias/porto/porto/interior/lagrimas-pintadas-nas-estatuas-do-porto-10597948.html 
mesma rua da Oficina Arara [15], dois projetos que colaboram regularmente. Assim, podemos considerar que estas produções - sendo individuais - fazem parte de um movimento coletivo que se alimenta e contamina mutuamente.

As produções têm também linguagens e estratégias discursivas particulares que pressupõem diferentes objetivos. Distinguimos três que nos parecem fundamentais: o uso do humor e da ironia, patente na performance de Ballesteros e Paim, nas ilustrações de Pedro Figueiredo ou no mural "Best European Destination". Ao subverter a ordem das coisas, ao provocar riso e espanto, contribuem para desconstruir discursos dominantes e abrir campos de possibilidades. Como explicam as duas protagonistas de $100 \mathrm{Lar}$, foi uma forma de "chamar à atenção" e "mostrar que ainda há espaços vazios" fora da "lógica neoliberal”. Outra estratégia evidente é a de gerar empatia e comoção. Vemos isso no projeto "Olhos Fechados" que nos incita a escrever cartas para alguém que já morreu, dando "visibilidade aos moradores que o Porto não quer ver" 22 ou no filme "Cães que ladram aos pássaros" que nos convida a "entrar" dentro da intimidade de uma família que acabou de ser despejada. A realizadora explica que os seus filmes partem sempre de experiências pessoais que "mexem" com ela e que, por isso, quis falar da gentrificação não como "números e estatísticas, uma coisa muito abstrata", mas a partir uma perspetiva "real" e "emocional". ${ }^{23}$ Uma outra modalidade é a da intimidação ou mobilização: é o caso da música "Porto Arder" impregnada de imagens e palavras de ordem contra a turistificação ou de "Circunvalação" que termina com um statement e um apelo: "pelo direito à cidade, gamamos", "faremos como sempre das tripas coração". Para a rapper o que faz não é para ser "música de fundo", mas sim para passar uma mensagem. "A arte serve para transformar os incómodos em beleza", "é um bocadinho uma digestão daquilo que nos incomoda." ${ }^{24}$

Outro aspeto a merecer realce é o contexto onde são expostas ou apresentadas. Identificamos neste grupo, três diferenças: espaço institucional, como a peça apresentada num teatro municipal; espaço público, como a street art ou performance; e espaço virtual, como as ilustrações do Pedro Figueiredo que não têm, até agora, saído do seu perfil pessoal no facebook, ainda que sejam frequentemente partilhadas por indivíduos e coletivos ativistas. Essas fronteiras não são estanques. "Circunvalação" da Capicua tanto pode ser ouvida online, como ser tocada numa sala de concertos ou numa concentração política. Um trabalho do Miguel Januário facilmente é fotografado e disseminado pelas redes sociais, ampliando a sua capacidade de expansão. Nesse sentido, as criações artísticas podem ter um carácter efémero ou perene. Se uma pintura na parede, facilmente é pintada de branco, mais difícil é queimar todas as edições de um álbum ou destruir o rasto de um documentário. No caso da peça de Tiago Correia, a efemeridade própria de uma peça teatral, apresentada em dois dias, foi contrariada quer pela polémica que daí adveio, quer pela edição em livro do texto da obra.

Associada a essas dimensões está a distinção entre trabalhos próximos do artivismo e aqueles realizados com financiamento ou propósitos comerciais. Há diferenças substanciais entre a pintura de uma faixa no contexto de uma manifestação ou a organização de uma exposição numa galeria de entrada livre; e filmes financiados pela CMP, músicas que reverterão em lucro para a artista ou um espectáculo de teatro para o qual é necessário comprar bilhete. Os motivos

22 Palavras de Marta Vidal numa publicação no facebook.

23 Https://www.dn.pt/cultura/leonor-teles-leva-a-gentrificacao-do-porto-ao-festival-de-cinema-de-veneza--11255891.html

24 https://www.sapo.pt/noticias/nacional/em-madreperola-capicua-rappa-sobre-coisas_5e27d96df000f$412 \mathrm{c} 3 \mathrm{a} 681 \mathrm{a} 8$ 
que movem os/as artistas serão necessariamente distintos, assim como o grau de autonomia na criação artística, levantando várias questões problemáticas. Quais serão os propósitos da autarquia neste apoio explícito? Podemos considerar esta uma forma de apropriação ou instrumentalização? (Lopes, 2013) Serão os artistas conscientes dessa ambiguidade? Terão liberdade para tomar decisões e conceber os seus projetos? A que preço? A polémica que se instalou em torno da peça "Turismo", financiada pela DGArtes e co-produzida pelo Teatro Municipal do Porto, é um exemplo de como essas fronteiras são ténues e ambíguas, colocando os artistas e as instituições em situações desconfortáveis e, por vezes, contraditórias. Por outro lado, o alcance e capacidade de disseminação que artistas mais reconhecidos usufruem colocam-nos dilemas. Apesar de sabermos que a rapper Capicua beneficiará da venda do seu disco, a verdade é que é uma estratégia bastante mais eficaz para colocar o assunto na praça pública do que qualquer performance ou exposição numa galeria "alternativa”.

\section{Discursos críticos sobre o turismo: aproximações e (outros) paradoxos}

Se relativamente à forma as quinze produções artísticas diferem bastante, já no que concerne ao conteúdo, os exemplos que trouxemos apresentam bastantes similaridades. Assentam em três argumentos principais: 1) o turismo contribui para a perda de identidade portuense; 2) destrói a cidade e alimenta a especulação; e 3) resulta em desigualdades e segregação socioespacial. Cada um dos argumentos contém também contradições relevantes que importa debater.

Em "Circunvalação", Capicua fala de pessoas e lugares que considera únicos na cidade (gunas, mulheres do Bolhão, Vandoma, ilhas ${ }^{25}$ ) celebrando o Porto "real, habitado, castiço, quotidiano". Tipicidade essa que é substituída por "lojas que são iguais a todas as outras cidades do mundo (...) mercearias gourmet com falsos bacalhaus de plástico à porta", em que "as velhas rotinas dos portuenses, os velhos lugares" vão-se descaracterizando e "acabam por se tornar uma coisa meia plástica, para inglês ver". ${ }^{26}$ Mais agreste, a banda punk Grito! canta: "abre mais um hotel e mais não sei o quê, até um buraquinho vira um tasco gourmet. O típico tripeiro está em vias de extinção e quem se fode sempre é o morcão ${ }^{27}$." Também a exposição "CriptoPorto" anuncia a morte da cidade, causada pelo encerramento dos tascos tradicionais, pelo desaparecimento dos sítios ocupados pelo povo e pela "limpeza" da cidade transformada para satisfazer o turista. Nestes e noutros discursos de luta contra a gentrificação, nota-se por vezes uma certa romantização da pobreza, do "porto podre"28, mas genuíno, de outrora. A idealização ou sobrevalorização da identidade portuense coloca-nos perante uma tensão entre autenticidade e xenofobia. Discursos como esses podem, eventualmente, correr o risco de acionar discursos xenófobos, dirigidos aos turistas ou a certo tipo de turistas (de determinada nacionalidade, com maior poder de compra ou que provocam distúrbios). Inscrições como "O Porto já não são tripas", "Ó turista, não me compres o meu ninho", "Tourists go home" ou "Fuck tourists" - dispersas em várias paredes da cidade - são um reflexo claro dessa turistofobia. Em período

25 Gunas é um epíteto do calão do norte do país para designar jovens urbanos das classes populares, geralmente percepcionados como intimidadores; Bolhão é um mercado tradicional do Porto; Vandoma é uma feira de produtos usados com quase 50 anos de existência; ilhas são casas típicas construídas para albergar a população operária.

26 Https://blitz.pt/videos/2020-01-26-Capicua-No-Porto-de-hoje-ate-o-bacalhau-a-porta-da-mercearia-e-de-plastico-VIDEO

27 Tripeiro e morcão são dois termos para nomear os habitantes do Porto, ainda que morcão tenha uma carga mais pejorativa, sendo associado a pessoas pouco ativas.

28 Durante um período, disseminou-se pelas paredes da cidade a expressão "Make Porto, Podre again" (Barbosa \& Lopes, 2019). 
de ascensão de políticas conservadoras e de extrema direita, não deixa de ser preocupante uma nova tendência para ideais identitários (regionalistas ou nacionalistas), numa defesa contra os estrangeiros que "invadem" a cidade invicta.

Outro argumento presente é de que o turismo destrói a cidade, promovendo a especulação imobiliária e a construção desenfreada. As fotografias de Luís Coelho dão conta disso, mostrando uma paisagem do Porto transfigurada por gruas, crateras e andaimes que em nada se assemelha aos postais ilustrados. Várias títulos contidos na publicação de "Contra Cidade" fazem também desse o principal argumento: "Ouve: este é o som de uma cidade a cair", "Desculpem o transtorno: tropeços da memória numa realidade em obras”. As ilustrações que intercalam os textos representam imagens apocalípticas: figuras disformes e turistas de apetite voraz; explosões, chamas, bombas que caem sobre os monumentos. O stencil "Cidade Líquida” de Miguel Januário contém também essa crítica, termo que inclusive deu o mote para um dos debates "Porto por Ponto", da rádio Manobras, onde este é comentador. Os artistas reconhecem que há duas faces da moeda. Luís Carvalho (3 Pontinhos) salienta que "houve muita recuperação, o que é bom. Mas desapareceu muito comércio tradicional". "Uma cidade é feita por pessoas, não por casas. Caso contrário perdemos a nossa identidade”. No seu entender, urge encontrar um "meio-termo" entre "uma cidade reabilitada mas habitada por portuenses ${ }^{29}$ ". Capicua admite que o "turismo cria emprego, recupera os edifícios" mas que "não pode ser à custa de uma perda da identidade e da expulsão das pessoas que sempre viveram" nesses sítios. Fala também em prioridades e regulação: [o município pode] "controlar as licenças do alojamento local, pode aproveitar o dinheiro da taxa turística", "manter os preços controlados, para controlar a voragem do turismo que come tudo à sua frente".

O último dos argumentos encontrado nestas produções artísticas é o do turismo como fonte de desigualdades. "Gentrificasamba", por exemplo, debruça-se sobre os privilégios do turista em contraste com os dos moradores que têm de sair das suas casas ou suportar a subida das rendas: "Já me disseram que os que moram em hotéis têm direito a roupa lavada, a cama arrumada e massagem nos pés. Não vejo a hora de sair do aluguel, quando a minha casinha for promovida a hotel (...) Se eu tivesse futuro à vista, já tinha investido há mais tempo na profissão de turista". "Rebenta a Bolha" ostenta também a divisão entre aqueles que lucram com a especulação imobiliária (investidores, proprietários) e aqueles que são esmagados pelos preços altos da habitação. O projeto "Olhos Fechados" foca-se nas consequências desiguais da turistificação, nomeadamente na segregação socioespacial. Para além do mural de grandes dimensões do Sr. Lapa, antigo morador falecido depois de uma ordem de despejo, vários cartazes foram afixados pelas ruas do Porto, com o mesmo rosto e perguntas incisivas: "Quanto custa uma vista para o rio? A habitação é um direito ou um investimento? Quem tem direito a morar no centro da cidade? É mais importante uma cidade onde se vive ou uma cidade onde se lucra?” Em baixo, a inscrição "Responda ao Sr. Lapa, Passeio das Virtudes, n 57, $2^{\circ}$ andar." Também sobre este tema podemos encontrar algumas contradições, algumas delas retratadas pela peça "Turismo". Nela uma jovem atriz tem um trabalho precário no sector do turismo e aluga o seu próprio quarto a visitantes estrangeiros para fazer face às despesas e prosseguir o sonho de ser artista. $\mathrm{O}$ fotógrafo estrangeiro que, a dada altura ocupa a sua casa, parece não se assumir enquanto "típico turista" mas beneficia das experiências proporcionadas pela rapariga: os passeios pela cidade ou o jantar tradicional confeccionado por ela. Ao mesmo tempo, os proprietários do apartamento

29 Entrevista a Luís Carvalho: https://www.publico.pt/2019/06/21/local/noticia/turismo-plastico-nao-serve-porto-tres-pontinhos-1877050 
passam dificuldades financeiras e vivem na periferia para conseguirem sobreviver no dia-a-dia. Isso levanta algumas questões: até que ponto contribuímos para a indústria do turismo? Serão turista e residente, proprietário e inquilino, categorias homogéneas? (Chabrol, 2016) Não serão os artistas, em grande medida, privilegiados, por terem capital cultural e social e outras estratégias de subsistência?

Os projetos que trouxemos para este artigo têm em comum o facto de serem protagonizados pela "Geração Milénio"30, mais qualificada que a anterior, porém marcada por vínculos laborais precários, dificuldades de inserção no mercado da habitação e por uma descrença generalizada no sistema político de representação. São a geração pós-25 de Abril para quem os sonhos e esperanças da revolução deram lugar à desilusão, agudizada com a crise e as políticas de austeridade (Ferreira, 2017). Assim, quando atrás discutíamos a tensão entre liberdade e institucionalização, vale a pena lembrar a precariedade que atravessa o universo artístico em Portugal (recibos verdes, trabalho informal e sazonal, dependência dos parcos financiamentos para a cultura) que não permite, de facto, que muitos/as artistas tenham margem suficiente para recusar trabalhos e encomendas. Assim, o contexto económico do país e o nível de vida dos seus habitantes é um aspeto a ter em conta quando discutimos sobre gentrificação.

Fruto dessas condições distintas - estar em situação mais ou menos precária, confiar mais ou menos nos processos ativistas ou na democracia - o modo como os artistas se posicionam na vida pública é também ele plural. Se alguns participam nas manifestações, outros preferem manter apenas o "ofício" de artista. Uns usam da sua notoriedade para passar uma mensagem, outros preferem o anonimato. Em todo o caso, todas/os eles criam a partir de um determinado propósito político e social situado entre a "denúncia e o anúncio"31.

\section{REFLEXÕES FINAIS E PISTAS PARA UM DEBATE FUTURO}

A utilização da arte como canal de denúncia e mobilização é uma prática antiga (Castellano \& Raposo, 2019). Habitando o mundo social e político, muitas/os artistas rebelam-se contra as injustiças e afirmam as suas posições, através dos meios que melhor dominam ou que mais satisfação lhes dão. Em Portugal, basta lembrar as canções de intervenção antes do 25 de Abril e durante o P.R.E.C.; a música "Parva sou eu" dos Deolinda - que deu mote ao protesto da "Geração à Rasca" - ou a trilogia "Mil e uma noites" de Miguel Gomes sobre os anos da Troika. Fazendo parte das resistências coletivas, estes artistas esbatem as fronteiras entre arte e ativismo (Mourão, 2015), (re)constroem possibilidades e alternativas e contribuem para expandir e multiplicar as suas reivindicações.

Os exemplos de produções artísticas que expusemos neste artigo reportam aos últimos dois anos, altura em que se começaram a sentir de forma mais intensa as consequências da gentrificação no Porto. Os artistas, tal como quaisquer cidadãos/as, vêem os seus espaços de encontro a ser encerrados e a renda das suas casas aumentar; sentem a necessidade de mudar para a periferia ou partilhar casa com amigos ou desconhecidos/as; percebem que as ruas, praças e lojas perdem os seus traços habituais para darem lugar a uma cidade-gourmet; participam - como

30 Só Pedro Figueiredo é mais velho, com 45 anos.

31 Referência ao conceito de "inédito viável" do educador Paulo Freire, no qual a utopia é entendida como uma síntese entre a denúncia (do que tem de ser transformado) e o anúncio (de alternativas). 
tantos outros/as - dos protestos e manifestações que, de quando em quando, vão assolando o espaço público.

Apesar de aqui as mostrarmos como um todo, os exemplos que trouxemos revelam precisamente que a "arte socialmente comprometida" se faz de diferentes gestos e tonalidades. Há quem faça uso da performance, música, cinema ou artes plásticas. Há quem crie as suas obras de forma espontânea, quase visceral, e outros que as preparam demoradamente. Há quem o faça junto com os outros e quem o faça individualmente. Há quem nunca assuma a autoria, outros que são financiados para dar corpo às suas criações. Eventualmente, terão até posicionamentos distintos sobre o rumo que a cidade toma e sobre as formas de o conter. Para Suzanne Lacy (2019) - célebre performer feminista - discutir o papel da/o artista implica percorrer todo um espectro que vai do artista enquanto experienciador ou repórter, ou seja, que baseia o seu trabalho nas experiências ou observações; ao artista enquanto analista, interpretando e construindo significados; até ao artista ativista que se envolve e participa nos movimentos. São todas essas nuances - toda essas complexidades e contradições - que quisemos trazer a debate.

Faltou-nos, porém, discutir a fundo o papel ambíguo que os artistas têm nos processos de gentrificação. Em cidades europeias, como Berlim, Barcelona ou Amesterdão ${ }^{32}$, tal como mais recentemente no Porto ou Lisboa, tem-se assistido a um movimento de artistas - muitos deles jovens e precários/as - para zonas pobres e/ou multiculturais da cidade. Usufruindo de rendas mais baratas, conseguem implantar os seus ateliês, galerias, lojas vintage ou vegan, produzindo uma nova cultura hipster e alternativa. O que acontece é que, em pouco tempo, esses bairros tornam-se lugares atrativos, os preços sobem e a população das classes populares vai sendo "naturalmente" erradicada. Na mesma linha, o designado artwashing (Schacter, 2014), ou lavagem pela arte, ancorada numa visão de "cidade criativa" e no paradigma das "indústrias culturais" (Guimarães, 2017) tem sido apontado como estando a legitimar ou mesmo produzir formas de gentrificação e, consequentemente, de desigualdade social. Mesmo as práticas mais disruptivas, designadas de artivistas, podem servir de complemento às "políticas de promoção mercantil de promoção da cidade" (Delgado, 2013) se não associarem um projeto "artisticamente radical" a um projeto "politicamente radical" (Krause, 2011). Em Madrid, grafittis como "tu street art me sube el alquiler", "morram, modernos", "pijos [riquinhos], fora do bairro) 33 ", dão conta da crescente intensidade desta discussão. Nas nossas descrições sobre o trabalho da Oficina Arara [15], do Atelier Logicofobista [2] ou do Quiosque do Piorio [19] no Bonfim, ou sobre os murais na Praça dos Poveiros [18] e nas Virtudes [16] - zonas onde o valor da habitação tem exponenciado e onde, habitualmente, se reúne o circuito alternativo e artístico do Porto - mostram como facilmente arte, ativismo e gentrificação se mesclam numa perigosa combinação. ${ }^{34}$

Procuramos neste artigo construir um mapeamento com pretensões quase históricas de algo que está a acontecer agora mas que tem raízes lá atrás. Falta-nos distanciamento para o analisarmos de uma forma crua e densa, para as enquadrarmos num quadro teórico e conceptual, e sobretudo para percebermos onde isto nos leva. Ainda assim, as produções artísticas que expusemos assumem-se como uma expressão das inusitadas formas através das quais ação e pensamento se unem através da linguagem inscrita no espaço. Ativam-se, pois, no embate entre diferentes conceções de "espaço produzido" (Lefèbvre, 2000): as representações do espaço que se encontram nas intencionalidades de experts e burocratas que planeiam, racionalizam e mo-

32 Ver p.ex. documentário "I am a tool of gentrification": https://vimeo.com/292780347

33 Https://brasil.elpais.com/brasil/2019/06/03/eps/1559569999_961348.html

34 Https://www.publico.pt/2020/02/10/fugas/noticia/bonfim-porto-bairros-cool-europa-guardian-1903565 
dificam a cidade conflitua com a imaginação das utopias e dos ativismos contra-hegemónicos. Mas são, ainda, manifestações pujantes do espaço vivido, ou terceiro espaço, na aceção de Soja (1996) desafiando os usos monolíticos, estandardizados e comercializados do urbanismo liberal.

Ao longo destas páginas, fomos mostrando como muitos/as artistas têm contribuído para gerar massa crítica e apelar à mobilização coletiva, mostrando como é possível aliar a função social a uma função estética da arte. O potencial destas práticas parece residir no facto de articularem as duas dimensões da crítica ao capitalismo (Boltanski \& Chiappello, 1999). Por um lado, uma "crítica social" assente nas desigualdades sociais, na opressão e no direito material à habitação. Por outro lado, uma "crítica estética" enquanto expressão criativa que desafia os valores do capitalismo (egoísmo, ganância, corrupção), baseada no direito imaterial à cidade. Sendo a gentrificação uma "questão ideológica, política" e o "processo de mudança urbana que melhor materializa a luta de classes no palco na/da cidade contemporânea." (Mendes, 2017: 489-490), importa reafirmar a necessidade de aliar as duas críticas ao capitalismo num esforço de o combater.

Na complexa tessitura de ambiguidades e contradições, espelham-se, ainda assim, contra-usos do espaço público (Leite, 2004), disputando a hegemonia visual e narrativa. Estas dinâmicas sinuosas, oblíquas, feitas de apropriações e inversões de sentido, jogando com a surpresa e a polissemia, criam uma "consciência do olhar" (Sennett, 1991), que se demora e se surpreende, abrindo interpretações outras e, questionando e difundindo leituras alternativas. Em certo sentido, são heterotopias práticas e realistas, colocações "absolutamente outras", "contestadas e invertidas", "espécie de utopias efetivamente realizadas" (Foucault, 2013), que nos obrigam a ter em conta diferentes mundos da vida e a repelir qualquer colete de forças de homogeneidade. Em suma, abrem a possibilidade de outra des)ordem no espaço.

\section{REFERÊNCIAS BIBLIOGRÁFICAS}

Antunes, Gonçalo, Madalena Corte-Real, Maria João Monteiro Gomes e Marianna Monte. 2019a. "Habitação nas áreas urbanas de Lisboa e Porto: Da comunidade aos decisores políticos”, Forum Sociológico, No Temático, 34.

. 2019b. "O memorando da Troika e o mercado de habitação em Portugal", Working paper de acesso reservado: 1-22.

Alves, Sónia. 2017. "Requalificação e gentrificação no centro histórico do Porto". Scripta Novva: Revista Electrónica de Geografia y Ciencias Sociales, XXI (557): 1-32.

Barbosa, Inês, e João Teixeira Lopes. 2019. "Descodificar as paredes da cidade: crítica à gentrificação e luta pela habitação no Porto", Sociologia: Revista da Faculdade de Letras da Universidade do Porto, 38: 6-29.

Boltanski, Luc, e Eve Chiapello. 1999. O novo espirito do capitalismo. São Paulo: WMF Martins Fontes.

Janoschka, Michael. 2018. “Gentrificación en España reloaded”. Revista Papers: Gentrificació i dret a la ciutat (60) 24:30.

Castellano, Carlos Garrido e Paulo Raposo. 2019. (org) Textos para uma história da arte socialmente comprometida. Lisboa: Documenta.

Chabrol, Marie, Anais Collet, Matthieu Giroud, Lydie Launay, Max Rousseau e Hovig Ter Minassian. 2016. Gentrifications. Paris: Éditions Amsterdam. 
Colomb, Claire, e Johannes Novy. 2017. (Eds) Protest and Resistance in the tourist city. New York: Routledge.

Delgado, Manuel. 2013. "Artivismo e pospolítica: sobre la estetizacion de las luchas sociales em contextos urbanos". Quaderns-e, 18 (2): 68-80.

Della Porta, Donatella, e Alice Mattoni (2014). Spreading protest: social movements in times of crisis. UK: ECPR Press.

Fernandes, José A. Rio, Pedro Chamusca, Thiago Mendes e Luís Carvalho. 2018. O Porto e a Airbnb. Porto: Book Cover Editora.

Ferreira, Vítor, Marina Costa Lobo, Jussara Rowland e Edalina Rodrigues Sanches. 2017. Geração Milénio? Um retrato social e político. Lisboa: Imprensa de Ciências Sociais.

Foucault, Michael. 2013. "De espaços outros”. Estudos Avançados, 27(79): 113-122.

Gusman, Inês, Pedro Chamusca, José Fernandes e Jorge Pinto. 2019. "Culture and Tourism in Porto City Centre: Conflicts and (Im)Possible Solutions”. Sustainability, 11 (5701): 1-21.

Guimarães, Regina. 2017. Desobedecer às indústrias culturais. Cadernos desobedientes, Porto: Cultra e Deriva Editores.

Krause, Adam. 2011. Art as politics: the future of art and community. Norway: New Compass Press.

Queirós, João. 2017. "A disappearing world: the ever-expandier frontier of gentrification through the eyes of Porto's historic centre long-time residents" em Abel Albet e Núria Benach (Eds), Gentrification as a Global Strategy: Neil Smith and Beyond, pp. 197-209. New York: Routledge.

Lacy, Susanne. 2019. “Território em disputa: para uma linguagem crítica da arte pública”, em Carlos Garrido Castellano e Paulo Raposo (org), Textos para uma história da arte socialmente comprometida, pp. 27-42. Lisboa: Documenta.

Lefébvre, Henri. 2000. La Production de l'Espace, Paris, Anthropos.

Leite, Rogério Proença. 2004. Contra-Usos da Cidade - Lugares e espaço público na experiência urbana contemporânea, Campinas, Editora Unicamp.

Lopes, João Teixeira. 2013. "Capitalismo artístico: quando a arte e a cultura ocupam o centro", Simbiótica, Ufes, 3: 1-15.

Mendes, Luís. 2017. "Gentrificação turística em Lisboa: neoliberalismo, financeirização e urbanismo austeritário em tempos de pós-crise capitalista 2008-2009”. São Paulo: Cadernos Metrópole, 19 (39): 479-512.

Mourão, Rui. 2015. "Performances artivistas: incorporação duma estética de dissensão numa ética de resistência". Cadernos de Arte e Antropologia, 4 (2): 53-69.

Miranda, Tiago. 2018. "The touristic Porto - gazing over the city", Sociologia: Revista da Faculdade de Letras da Universidade do Porto, Nr temático, 8: 72-91.

Schacter, Rafael. 2014. "The ugly truth: Street Art, Graffiti and the Creative City". Art \& the Public Sphere, 3 (2): 161-176.

Schuerman, Mathew (2019) Nerwcomer: gentrification and its discontents. Chicago: The University of Chicago Press.

Sennet, Richard. 1991. La Conscience de l'oeil em AA.VV, L'Espace du Public - les compétences du citadin, Paris: Plan Urbain.

Smith, Neil. 1996. The New Urban Frontier: Gentrification and the Revanchist City. Abingdon: Routledge.

Soja, Edward. 1999. Thirdspace. Journeys to Los Angeles and Other Real-and-Imagined Places. Oxford: Blackwell 


\section{“OPORTO IS NOT FOR SALE”: RESISTANCE TO GENTRIFICATION THROUGH ARTISTIC PRODUCTION IN THE POST-AUSTERITY PERIOD}

Exploring the hypothesis that touristification in Portugal has particularities related to the country's economic crisis and subsequent austerity policies, this article explores artistic activities to guarantee the right to housing in Oporto. It focuses on the so-called "socially committed art", presenting fifteen projects carried out between 2018 and early 2020. On the background of these artistic activities, the article discusses the process of creation, context and communicational strategies, underlying discourses and objectives, highlighting tensions and paradoxes. Finally, it reflects on the role of art and artists for the establishment and dissemination of a critique of gentrification.

Keywords: artists, resistance, housing rights, gentrification

Recebido em: 2019-09-06

Aceite em: 2020-05-27 